\title{
O saber resíduos sólidos de serviços de saúde na formação acadêmica: uma contribuição da educação ambiental*
}

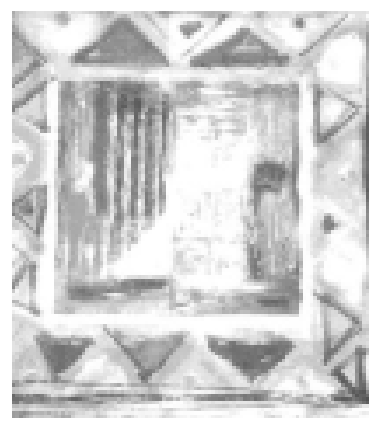

Luciara Bilhalva Corrêa ${ }^{1}$

Valéria Lerch Lunardi

Suzana Maria De Conto ${ }^{3}$

Maria do Carmo Galiazzi ${ }^{4}$

CORREAA, L. B. et al. The understanding of solid waste from healthcare services in academic education: a contribution to environmental education. Interface - Comunic., Saúde, Educ., v.9, n.18, p.571-84, set/dez 2005.

This article shows how the problematic of solid waste from healthcare services is being approached in undergraduate courses in the healthcare field. The data was obtained from coordinators, professors and students of Dentistry, Veterinary Medicine, Nursing and Obstetrics, and Medicine courses offered by a public university in the south of Brazil. It takes into account the need for an educational reform that should include in the pedagogical process a grasp of integrality, articulation, dialogue and problematization, so as to prepare the future professionals for instrumentalizing and facing the issue of solid waste from healthcare services with responsibility and commitment.

KEY WORDS: educational process. higher education. solid waste. health services. environmental education. social commitment.

Investiga-se como a abordagem da problemática dos resíduos sólidos de serviços de saúde vem sendo construída no processo de formação dos cursos de graduação da área da saúde. Os dados foram colhidos junto a coordenadores, docentes e estudantes dos cursos de Odontologia, Medicina Veterinária, Enfermagem/Obstetrícia e Medicina de uma instituição pública de ensino superior da região sul do país. Considera-se a necessidade de uma reforma no ensino, a fim de incluir nos processos pedagógicos novas compreensões de integralidade, articulação, diálogo, problematização, de modo a preparar os futuros profissionais para a instrumentalização e para o enfrentamento da problemática dos resíduos sólidos de serviços de saúde, com responsabilidade e comprometimento.

PALAVRAS-CHAVE: processo de formação. ensino superior. resíduos sólidos. serviços de saúde. educação ambiental. compromisso social.

* Elaborado a partir de dissertação de Mestrado (Corrêa, 2005).

${ }^{1}$ Economista Doméstica, Programa de Pós-Graduação em Educação Ambiental, Departamento de Educação, Fundação Universidade Federal do Rio Grande/FURG. <luciarabc@terra.com.br>

${ }^{2}$ Enfermeira, Professora, Programa de Pós-Graduação em Educação Ambiental, Departamento de Enfermagem/FURG. $<$ vlunardi@terra.com.br>

${ }^{3}$ Engenheira Química, Pesquisadora, Instituto de Saneamento Ambiental, Departamento de Engenharia Química, Universidade de Caxias do Sul. <smcmande@ucs.br>

${ }^{4}$ Química, Professora, Programa de Pós-Graduação em Educação Ambiental, Departamento de Química/FURG. <carmo@mikrus.com.br>

${ }^{1}$ Av. Juscelino K. de Oliveira, 1962/307 Bloco F 
Introdução

$\mathrm{Na}$ atualidade, enfrentamos sérios desafios, dentre os quais, a complexidade $e$ diversidade existente na problemática ambiental. Entre as fontes de degradação ambiental, os resíduos sólidos gerados na área da saúde representam uma peculiaridade importante; quando gerenciados inadequadamente, oferecem risco potencial ao ambiente. Essa problemática vem sendo cada vez mais objeto de preocupação de órgãos de saúde, ambientais, prefeituras, técnicos e pesquisadores da área. Isso se verifica pela quantidade de legislações e referências existentes, que preconizam condutas de gerenciamento dos resíduos nos locais onde são prestados serviços à saúde (Coelho, 2000).

É inquestionável a necessidade de implantar políticas de gerenciamento dos resíduos sólidos de serviços de saúde (RSSS) nos diversos estabelecimentos de saúde, não apenas investindo na organização $e$ sistematização dessas fontes geradoras, mas, fundamentalmente, mediante o despertar uma consciência humana e coletiva quanto à responsabilidade com a própria vida humana e com o ambiente. Nesse sentido, os profissionais devem preocupar-se com os resíduos gerados por suas atividades, objetivando minimizar riscos ao ambiente e à saúde dos trabalhadores, bem como da população em geral. Isso depende, em parte, da formação desses profissionais. Sabe-se que há poucos espaços de estudo sobre a temática e pouco investimento em pesquisa com esse enfoque. As soluções dependem de uma série de decisões tomadas em diferentes níveis do sistema, tais como profissionais formados de maneira diferente daquela compartimentalizada existente nas universidades (Coelho, 2003; Schneider et al., 2002; Stédile et al., 2000; Formaggia, 1995).

É possível que a não inserção da abordagem dos RSSS no processo de formação dos futuros profissionais seja um aspecto importante para justificar o que acontece hoje em relação a esses resíduos, tanto nos estabelecimentos de saúde, como no meio ambiente.

Diante disso, parece ser relevante problematizar essa questão, num entendimento de que, para implantar técnicas de gerenciamento de resíduos nas diferentes fontes geradoras da área da saúde, faz-se necessário um investimento em todos os profissionais que atuam nos âmbitos da saúde, de forma a prepará-los e instrumentalizá-los para lidar com essa questão.

Assim, são objetivos deste estudo: a) conhecer como vem ocorrendo o processo de formação do profissional da área da saúde em relação ao fenômeno RSSS; b) conhecer como o conteúdo RSSS vem sendo desenvolvido nas atividades curriculares; c) conhecer como vem ocorrendo a vivência da abordagem dos RSSS nos diferentes âmbitos do processo de formação.

\section{Metodologia}

Trata-se de uma pesquisa qualitativa (Minayo, 1999), realizada em uma instituição federal de ensino superior localizada no sul do país, enfocando os seguintes cursos de graduação da área da saúde: Medicina Veterinária (MV), Medicina (M), Enfermagem/Obstetrícia (E/O) e Odontologia (O).

Participaram como sujeitos, os coordenadores de colegiados dos quatro 
cursos; três professores, sendo dois de disciplinas específicas, em que ocorre o desenvolvimento do saber objeto de estudo, e 14 acadêmicos dos respectivos cursos de graduação: quatro de (O), três de (MV), três de (M) e quatro de (EO).

Para a obtenção dos dados, foi utilizada a entrevista semi-estruturada $e$ a análise documental. Nas entrevistas foram enfocados, dentre outros, as etapas na abordagem dos resíduos; vivências em atividades teóricas e práticas; fragilidades e/ou facilidades na abordagem dos RSSS no processo de formação; apresentação do curso, grade curricular e projeto político-pedagógico; desenvolvimento do conteúdo e metodologia referente aos RSSS na disciplina; referências e fontes utilizados para ministrar o conteúdo dos RSSS.

Inicialmente realizamos a análise documental dos planos políticopedagógicos dos cursos em estudo, das grades curriculares e dos planos de ensino das disciplinas apontadas pelos coordenadores como as que abordariam os RSSS. A análise documental subsidiou, também, a realização das entrevistas, no sentido de conhecer como a abordagem dos RSSS vem ocorrendo no processo de formação dos cursos.

No que se refere aos aspectos éticos, o projeto de pesquisa foi aprovado pela Comissão de Ética em Pesquisa da Santa Casa de Misericórdia de Pelotas.

A partir da análise de conteúdo dos dados, proposto por Moraes, (2003), foram construídas duas categorias:

A abordagem dos resíduos sólidos de serviços de saúde em vivências teóricas e práticas no processo de formação A "formação para a abordagem dos RSSS numa perspectiva teórica" aborda o vivido em disciplinas que enfocam este conteúdo, seja explicitamente nos planos de ensino ou de modo implícito no desenvolvimento de outros conteúdos em diferentes disciplinas.

Em relação à abordagem dos RSSS descrita em planos de ensino, destacamos os cursos EO, com a disciplina Saúde Ambiental; e o de MV com a disciplina Saneamento. Apesar da relevância deste dado para o processo de formação dos cursos, os entrevistados apontaram algumas fragilidades, além de aspectos positivos que vêm ocorrendo nessas disciplinas.

Os sujeitos do Curso EO parecem ter uma abordagem dos RSSS mais abrangente do que os do Curso $M V$, apesar de aparentemente ainda não terem a compreensão do processo como um todo:

...Para mim no caso, seria: O que é? Por que? Qual é a vantagem?
Qual é a desvantagem que isso vai acarretar futuramente. Porque
elas (professoras) dizem: tem que fazer isso, separar o contaminado
do não contaminado; mas não é explicado o porque de fazer isso,
porque a gente tem que contribuir com isso, o benefício que vai
trazer. Qual a vantagem? Como é feita a coleta? Qual o custo para
instituição? São coisas que passam. Depois da coleta vai pra onde?
Como se faz? Dessa forma, eu acho que cria uma consciência na
gente, aí quando tu vai fazer, tu pensa mais, senão fica muito
mecânico só... (Aluna 2/EO)

Parece que o que é apontado pelos alunos, como falta de profundidade na 
abordagem desse conteúdo, pode tratar-se da falta de articulação das etapas trabalhadas às demais do manejo de resíduos, bem como das possíveis implicações de um manejo inadequado para a saúde dos indivíduos e a preservação ambiental. Daí, a necessidade de uma visão sistêmica, no processo de ensino, de modo que favoreça aos alunos um pensamento relacional, interligado, numa visão interdisciplinar, indicando que tudo que existe, co-existe e que nada existe fora de suas conexões e relações (Moraes, 2004; Morin, 2002).

Já no Curso $M V$, a abordagem dos RSSS ocorre com o desenvolvimento do conteúdo resíduos sólidos; apesar de os alunos referirem que foi mais enfatizado o tratamento e o destino dos resíduos. Assim, apesar de relevante tal enfoque, há de se considerar as demais etapas e a responsabilidade dos profissionais da saúde perante a geração de resíduos: minimização; reciclagem; segregação; manejo; acondicionamento; coleta $e$ armazenamento. Aqui surgem indagações sobre como esse conhecimento é desenvolvido com os alunos. Sua formação ocorre de uma forma problematizada, em consonância com o mundo real da prática da profissão?

O conhecimento pertinente é o que é capaz de situar qualquer informação em seu contexto, de maneira globalizada, articulada. Sendo assim, para além dos conteúdos dos RSSS que as disciplinas Saúde Ambiental e Saneamento abordaram, consideramos relevante que esse saber não seja acumulado, empilhado, depositado nos alunos, mas sim problematizado, articulado com as demais disciplinas, permitindo ligar os saberes e dar-lhes sentido com as demais etapas do processo de formação, pois uma inteligência incapaz de perceber o contexto fica cega, inconsciente e irresponsável (Morin, 2002).

O conhecimento parcelado dos RSSS a que os acadêmicos se referem pode se dar pela (des)articulação dessa abordagem com as demais etapas do processo de formação e com os outros conteúdos das demais disciplinas, impossibilitando que os acadêmicos realizem a conexão do que aprendem com o restante do processo e também ao longo de sua vida profissional:

...por que tem disciplinas que a gente vê uma vez só, e não vê mais (...) é falado, mas depois os outros professores, não ligam esse conhecimento com suas disciplinas, e essa dos resíduos mesmo, que eu me lembre, só na disciplina de Saúde Ambiental... (Aluna 1 /EO)

$O$ retalhamento existente entre as disciplinas torna impossível apreender o que é "tecido junto", isto é, o complexo. Sendo assim, além da fragmentação existente no ensino, torna-se necessário e urgente reformar o pensamento, de maneira a resgatar nossa própria condição de seres humanos, ou seja, fazse necessária a compreensão de que nossas ações têm relações com as diferentes dimensões da realidade, que tudo está interligado, situando o ser humano como parte desse contexto maior. É preciso não isolar os objetos de seus contextos, mas sim unir, despertando a curiosidade, o espírito crítico, a dúvida e a aptidão para sempre interrogar: "vivemos numa constante 
incerteza", e por isso o sistema de ensino deve preparar para responder aos desafios da globalidade e da complexidade na vida cotidiana, social, política, nacional e mundial (Morin, 2002).

Pimenta E Anastasiou (2002, p.28) apresentam o

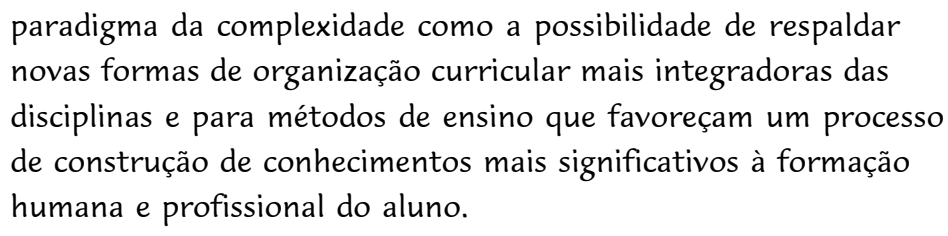

Os saberes separados, fragmentados, compartimentalizados, comumente apresentados e desenvolvidos em disciplinas existentes no ensino superior, mostram-se ainda mais inadequados, à medida que hoje precisamos pensar a realidade com problemas cada vez mais polidisciplinares, globais $e$ planetários. Assim, a abordagem de qualquer conteúdo tratado de maneira integral no processo de formação pode contribuir para um outro pensar dos profissionais da saúde, numa perspectiva de integralidade.

Outra fragilidade ressaltada pelos docentes e alunos refere-se ao número de horas das disciplinas em EO, pois foi designada apenas uma hora, sob a forma de apresentação de seminário pelos alunos; enquanto na $M V$ foram designadas três horas para o conteúdo dos resíduos, inserindo-se aí uma pequena parte para os RSSS:
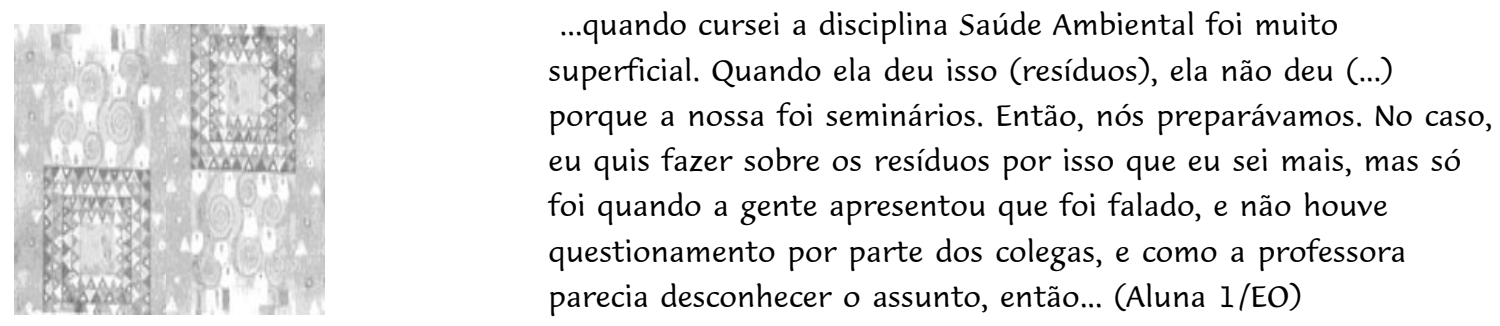

O tempo designado para o desenvolvimento de um conteúdo numa disciplina pode estar associado a vários elementos, como sua importância no processo de formação profissional, a importância dos demais conteúdos da disciplina, sua necessidade para o desenvolvimento posterior de outros conteúdos, referências disponíveis, até o domínio desse saber pelo docente, dentre outros.

Entretanto, se o ensino possibilitasse o relacionamento $e$ a interação de uma disciplina com outra, é provável que o tempo para o desenvolvimento dos conteúdos não fosse um limitante. De acordo com Morin (1999), faz-se necessário substituir um pensamento que está separado por outro que estabeleça vínculos. Para tanto, "a missão primordial do ensino e o desafio para os formadores implica muito mais em aprender a religar e, ao mesmo tempo, problematizar o conhecimento" (p.13).

É possível perceber que no desenvolvimento do seminário não foi criado um espaço de reflexão e discussão sobre a abordagem dos RSSS, como: a geração diária desses resíduos em um estabelecimento de saúde e nas 
faculdades; os diferentes materiais utilizados nessas instituições; sua destinação, os acidentes ocupacionais decorrentes do seu manejo; o compromisso social $e$ as questões éticas relacionadas a essa problemática.

De acordo com Abreu \& Maseto (1990, p.76), o seminário como uma estratégia de ensino "...gira em torno de um tema a ser estudado em profundidade a partir de diferentes ângulos, pelos alunos que, a seguir, reúnem o resultado desses estudos parciais e o sintetizam, chegando a uma conclusão". Assim, exige do professor, essencialmente, capacidade de organização, síntese e um adequado envolvimento com a classe, implicando manter a discussão aberta, que cada aluno expresse sua opinião, suportando as pausas, favorecendo a integração grupal entre os próprios alunos.

Já em Saneamento, foi empregada a aula expositiva, e a abordagem ficou centrada na fala do professor, com os alunos numa posição predominantemente de escuta, aparentemente sem argumentar sobre o assunto, não ocorrendo espaços de discussão sobre o conteúdo RSSS, confirmando o referido por Godoy (1997, p.76) de que "numa aula expositiva os estudantes podem ter a oportunidade de perguntar ou de participar numa pequena discussão, mas em geral não fazem mais do que ouvir e tomar apontamentos".

Considerando as múltiplas dimensões passíveis nessa abordagem, podem ser inúmeras as questões levantadas, em especial, no plano da ética. Uma ética integral traduz a responsabilidade do ser humano consigo mesmo, com os outros, com a natureza, associada a um sentimento de solidariedade que o liga aos demais seres viventes e não viventes e à totalidade do mundo. É uma maior responsabilidade em relação à vida, ao corpo humano e a toda ordem criada. Uma responsabilidade em relação ao todo, em que cada um, aluno e professor, assume sua parcela (Moraes, 2004). Sendo assim, tornase relevante destacar a pertinência do tema pesquisado para a educação ambiental, visto que o fenômeno RSSS, como de qualquer outro tipo de resíduo, está relacionado ao compromisso social de quem o gera, suas possibilidades e dificuldades de minimização, de reaproveitamento, segregação, dentre as demais etapas e implicações ecológicas de nossas ações e omissões. Esse compromisso traduz uma nova forma de se relacionar com o mundo. É preciso pensar complexo, ou seja, necessitamos de um pensamento mais abrangente para melhor compreender a sociedade, a natureza e a vida, só assim vamos entender que tudo está interligado, que somos parte do todo e o todo também é parte de nós; que tudo o que fazemos, ou não, relaciona-se com uma totalidade maior do que nós $e$ nossos atos (Morin, 2002).

A formação generalista, humanista, crítica e reflexiva é proposta nas Diretrizes Curriculares Nacionais, tornando-se necessário rever o modo como as metodologias são adotadas pelos docentes no processo de ensino dos cursos. É preciso estar aberto aos desafios da incerteza de nossas atividades no cotidiano, questionar constantemente fazeres, de modo que processos pedagógicos estejam permanentemente em desacomodação, sob um olhar indagador, de interrogação, de dúvida.

Em uma formação em que a crítica $e$ a problematização não sejam estimuladas, os acadêmicos podem não perceber a geração de resíduos e seu 


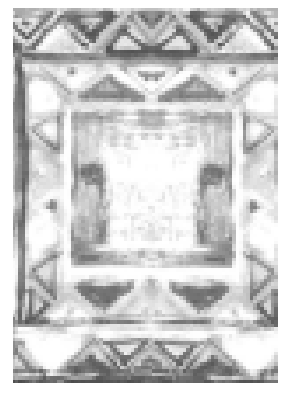

destino, tanto no âmbito da faculdade, quanto em outros, não reconhecendo as implicações para o ambiente; daí a pertinência da relação deste estudo com a educação ambiental pautando-se em um senso crítico, reflexivo, sob um enfoque holístico, de que tudo está interligado (Berna, 2001).

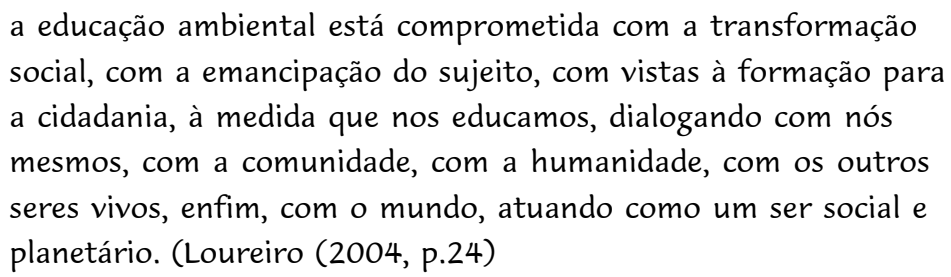

Foi evidenciado, também, que os docentes da disciplina Saúde Ambiental previam visitas a locais onde os alunos pudessem visualizar a abordagem dos resíduos, como galpões de triagem de resíduos, empresas de coleta $e$ tratamento dos resíduos do setor de saúde, aterro controlado do município, com o propósito de alcançar uma maior apreensão do conhecimento, porém, devido à falta de verbas na instituição pública, não conseguiram financiar o transporte dos alunos para esse fim. Parece importante, entretanto, os docentes das disciplinas perceberem que não é imprescindível sair da instituição para visualizarem a abordagem dos RSSS, visto que o Curso EO se desenvolve na mesma área do Ambulatório do Curso de Medicina, com atendimento à população, onde há a geração desses resíduos. O Curso $M V$ também se desenvolve próximo ao Hospital Veterinário, onde acontecem procedimentos em animais, portanto, resíduos também são gerados no local.

No mesmo ambiente de desenvolvimento das disciplinas, a abordagem dos RSSS pode ser observada, analisada e problematizada pelos alunos, favorecendo o desenvolvimento da sua consciência crítica, a reflexão sobre o que esse saber tem a ver com o exercício profissional, despertando sua responsabilidade e compromisso social. Entretanto, para isso, os docentes precisam articular o conteúdo teórico com esses espaços de vivência prática no âmbito da instituição, suas aproximações, afastamentos, possibilidades de enfrentamento. As Diretrizes Curriculares dos Cursos de Graduação CNE/CES $n^{\circ}$ 3, 4 e $n^{\circ}$ 3, 105 (Brasil, 2001a, 2001b, 2002a, 2002b) enfatizam que é imprescindível a articulação das atividades teóricas e práticas, desde o início e permeando toda a formação, de forma integrada $e$ interdisciplinar.

A "formação para a abordagem dos RSSS no enfrentamento com a prática" demonstra como vem ocorrendo a abordagem dos RSSS, mediante vivências práticas experienciadas pelos sujeitos no processo de formação que, em sua grande maioria, acontecem em estabelecimentos de saúde, portanto, mais próximos do mundo real, onde os acadêmicos irão exercer sua profissão.

Os dados foram organizados de acordo com as etapas do processo do manejo dos RSSS, ou seja, geração, segregação, acondicionamento, armazenamento, coleta, tratamento e disposição final. Também procuramos 
articular as etapas do manejo não mencionadas nos depoimentos, como a minimização e a reciclagem.

Parece ter ficado bastante evidente que os alunos têm noção de algumas das etapas do manejo, de sua relevância e implicações, porém são noções que se mostram fragmentadas, isoladas. Concomitantemente, expressam a necessidade e o desejo de articular o processo da abordagem dos RSSS como um todo. Um pensamento baseado na totalidade, no entanto, capta as relações, inter-relações e implicações mútuas, os fenômenos multidimensionais, as realidades que são simultaneamente solidárias e conflitivas, que respeitem a diversidade ao mesmo tempo que a unidade, um pensamento organizador que conceba a relação recíproca de todas as partes (Morin, 1999).

No que se refere à etapa de geração de resíduos, os estudantes dos cursos $E O$ e $M$ referiram vivência em aula prática:

\footnotetext{
...na aula de anatomia no $1^{\circ}$ semestre, a gente gerou um monte de luvas (...) no final de cada aula a gente botava dentro das bombonas plásticas.... (Aluna 3/EO). ...eu até ficava pensando, pra onde vai esse monte de luva. O que acontece depois daqui, mas nunca perguntei ao professor sobre isso, nunca mesmo...(Aluno $1 / M$ ).
}

- r- sível que, se desde o início do processo de formação essa questão fosse problematizada, mostrando as implicações e a relevância das diferentes etapas do seu manejo, articulando com os demais espaços que o acadêmico possivelmente irá vivenciar na sua vida prática, poderia ser alcançada uma melhor compreensão e instrumentalização para seu enfrentamento nas demais etapas da formação como também para sua vida profissional.

Ao iniciarem atividades práticas, em três cursos, EO, $O$ e $M V$, os alunos referiram que experienciaram um processo de orientação em relação à segregação e ao acondicionamento dos RSSS, porém expressam questionamentos acerca da sua falta de compreensão da totalidade, demonstrando que, apesar de terem entendido o processo, se vêem, como futuros profissionais, bastante inseguros de como agir no mundo da prática real.

As etapas de segregação e de acondicionamento são de extrema relevância para a continuidade de um adequado processo de manejo, o que implica a colaboração e o comprometimento de todos os envolvidos, já que sua segregação traz como benefício: a) minimizar a geração de resíduos; b) permitir seu manuseio, tratamento e disposição final adequados conforme sua categoria; c) minimizar os custos empregados no seu tratamento e na disposição final; d) evitar a contaminação de uma grande massa de resíduos por uma pequena quantidade perigosa; e) separar os resíduos perfurantes $e$ cortantes, evitando, assim, acidentes no seu manejo; e f) comercializar os resíduos recicláveis (Schneider, et al. 2004; Takayanagui, 1993).

Os estudantes da $M V$ também referiram orientação por parte do professor; no entanto, identificaram e vivenciaram problemas para proceder à segregação devido à falta de material adequado para o acondicionamento:

...nessa monitoria lá no hospital veterinário, eu via que lá faltava 
material às vezes; às vezes, não tem saco, e nem caixa para as agulhas. Então, a caixa antiga ta transbordando, de material, é difícil assim, então a gente acaba botando tudo na mesma lixeira... (Aluno 3/MV).

Aqui cabe outro questionamento: esse futuro profissional está sendo levado a pensar sobre seu fazer, pautado numa consciência ética, de responsabilidade e comprometimento com a qualidade de vida do ambiente? Se nos direcionarmos para o projeto político-pedagógico e as diretrizes curriculares nacionais dos cursos de graduação em estudo - CNE/CES no 3, 4 e $n^{\circ}$ 3, 105 (Brasil, 2001a, 2001b, 2002a, 2002b), estes prevêem a formação de um profissional generalista, com sólida formação técnico-científica, humanista e ética, com conhecimentos, habilidades e comportamentos que possibilitem decidir e atuar com segurança e propriedade na promoção da saúde e na prevenção, de modo a atender às necessidades sociais, de forma sustentada, promovendo a qualidade de vida.

$\mathrm{O}$ aparente descomprometimento com o ambiente e sua segurança não implica, comumente para as pessoas envolvidas, uma penalização pelas suas ações. No entanto, a questão dos RSSS é algo maior, extrapola o fazer individual, implica uma consciência ética, de responsabilidade com o meio ao qual pertencemos, de exercício de cidadania, de respeito aos outros. Daí a relevância da educação ambiental, por ser uma educação que tem por propósito formar cidadãos com consciência de direitos e deveres e com consciência local e planetária, com base no espírito crítico e inovador, promovendo a transformação e a construção da sociedade em uma perspectiva holística (Gadotti, 2000).

Alunos da $O, E O$ e $M$, e um professor da $M V$ referiram dificuldades em relação ao armazenamento dos resíduos:

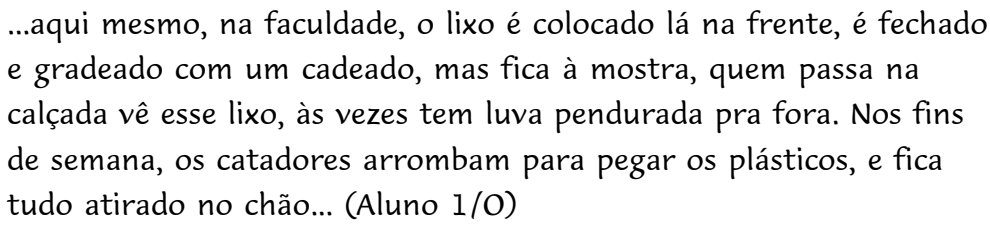

Assim, não são previstos espaços para a estocagem da geração de resíduos resultantes das atividades da saúde, o que também foi identificado por Mandelli (1997), quando realizou um estudo sobre o manejo dos resíduos sólidos urbanos no âmbito das residências. Provavelmente os RSSS não sejam uma preocupação apenas dos diversos profissionais, da área da saúde, como também das demais áreas do conhecimento, como da engenharia, arquitetura, dentre outros.

Retomando novamente os projetos político-pedagógicos dos cursos, é possível perceber que estes se pautam por uma formação fundamentada nos princípios da ética, do respeito e da responsabilidade social, em uma perspectiva de integralidade, de modo que o profissional seja capaz de trabalhar coletivamente no âmbito de sua profissão e na sua vida cotidiana, atuar na melhoria da qualidade de vida, defender e preservar a vida, estabelecer relações 
com o contexto social, reconhecendo a estrutura e as formas de organização, suas transformações e expressões com a construção da cidadania, de um ser reflexivo, participativo e crítico, em relação à realidade. Assim, essas condutas em relação ao armazenamento inadequado, conforme a fala $1 / O$, expondo resíduos a ações de pessoas que talvez desconheçam seus perigos $e$, ainda, suas possíveis implicações para o meio, estão atreladas a uma postura ética, de respeito e responsabilidade social, de exercício de cidadania, de preservação e promoção da qualidade de vida. Essas e outras questões levantadas necessitam ser analisadas no processo de formação, a fim de rever sua contribuição para a formação de um sujeito capaz de transformar a realidade dos problemas do cotidiano.

Desse modo, percebemos a relevância da educação ambiental no sentido basicamente de uma discussão, tematização e reapropriação de certos valores, como éticos, de cidadania, de respeito e de responsabilidade e compromisso social que, muitas vezes, não estão no nível mais imediato de consciência, mas encontram-se reprimidos ou recalcados no decurso de um longo processo histórico (Grün, 1996).

Em se tratando da coleta dos resíduos sólidos de serviços de saúde, os estudantes da $E O$ referiram o risco de acidentes ocupacionais associado a essa etapa. Geralmente nos locais onde há produção de resíduos, a coleta interna é realizada pelos funcionários da higienização:

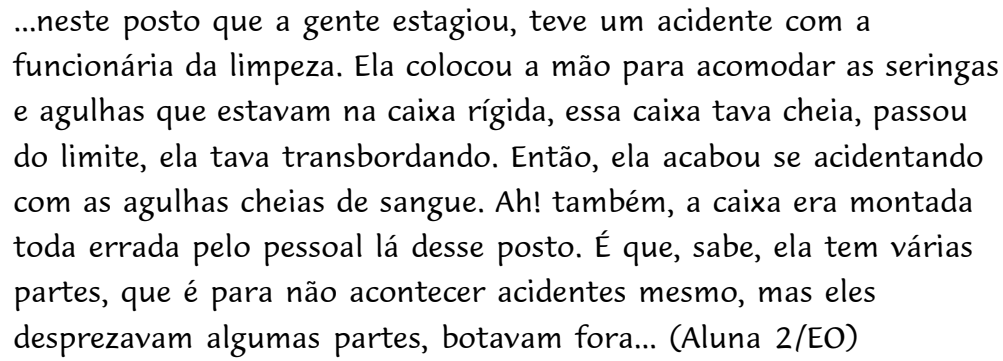

Observamos que, em geral, os acidentes atrelados aos resíduos principalmente associados a perfurantes e cortantes não são comentados e tampouco há uma discussão sobre o ocorrido nos âmbitos de vivência prática. Esse agir de forma descompromissada com a realidade remete-nos a questões da ética, em relação à responsabilidade do individuo consigo mesmo e com os outros, pautada por valores fundamentados na solidariedade e na responsabilidade em relação à vida, ao corpo humano e ao ambiente. Uma responsabilidade em relação ao todo, em que cada um assume sua parcela. Falar em ética implica falar em valores, que são parâmetros que norteiam as relações entre indivíduos e a sociedade, entre meios e fins. Os valores, ao invés de serem ensinados, necessitam, na realidade, ser vividos no cotidiano de cada um, nas suas diferentes atividades e a ética precisaria estar presente na essência do ato de educar (Moraes, 2004).

Quanto ao tratamento dos resíduos, um sujeito apontou para essa etapa:

...aqui, nós temos um forno, a gente sabe que ele não está nos

padrões certos, mas o que temos é isso por enquanto. Todos os 
resíduos contaminados do hospital veterinário são queimados lá, agora o forno está quebrado. Então nós não estamos conseguindo tratar os resíduos, eles estão acumulados lá fora, longe daqui do hospital... (Docente 1/MV)

Parece que a forma de tratamento adotada para os resíduos gerados é a incineração; no entanto, como o equipamento aparentemente apresenta problemas, o sujeito aponta a disposição final desses resíduos num outro local, possivelmente de forma inadequada. Também como destino final, outro sujeito faz referência ao resíduo líquido, gerado nas aulas práticas:

...eu tenho aqui a questão do descarte dos reveladores. Eu sei que
tem agora uma legislação sobre isso, mas ainda não pude
ver...sabe pra onde sai o nosso? Eu não sei pra onde vão. Tem
uma canalização, mas vai não sei pra onde, mas eu sei que é um
resíduo perigoso, mas foge aos nossos olhos. Então a gente não
vê e também procura não se preocupar muito...(Docente $2 / \mathrm{MV}$ )

O depoimento do professor demonstra que, apesar de ter identificado o problema do descarte inadequado dos resíduos que resultam das atividades práticas em sua disciplina, parece não haver uma preocupação concreta de se envolver com esse problema e de buscar soluções. Cabe destacar que os reveladores são considerados resíduos químicos, estando na classificação de resíduos perigosos devido a sua composição conter metais pesados, conforme a Norma Técnica Brasileira - NBR 10.004 (ABNT, 2004). Em vez de ser descartado, esse resíduo deveria ser acondicionado e encaminhado ao fabricante para posterior recuperação do metal prata.

O comprometimento com os resíduos gerados pelas diferentes atividades é parte do exercício de cidadania e responsabilidade social. Se agirmos de forma inadequada, possivelmente, esse nosso modo de agir pode não nos afetar. Daí, seu manejo constituir muito mais uma questão de consciência ética.

É importante destacar que na IFES em estudo, inexiste uma política voltada para o gerenciamento de todos os resíduos resultantes de suas atividades, apenas ações isoladas em alguns departamentos da instituição que não contemplam todas as etapas de um adequado manejo. Cabe ressaltar que a discussão referente ao gerenciamento dos resíduos nas IES brasileiras é recente.

\section{Considerações finais}

A questão dos RSSS, como qualquer outra que vem colaborando para a agressão ao meio ambiente, parece suscitar a emergência de uma nova postura ética, de renovação de valores, cidadania, compromisso com o social, num entendimento de que tudo faz parte da grande teia da vida, implicando uma nova consciência, de responsabilidade e comprometimento, em nossas ações, no nosso agir, na nossa forma de perceber e de viver e conviver nesse ambiente, que nos constitui e que constituímos.

Entre outros aspectos, cabe à educação instrumentalizar o educando para 
que possa perceber o verdadeiro sentido das coisas, evoluir e aprender a fazer escolhas mais conscientes e responsáveis no seu fazer. Para isso, a educação necessita considerar que indivíduo e meio constituem uma totalidade, que nossas ações têm implicações para o meio do qual fazemos parte, despertar uma consciência de que temos um destino comum, um sentimento de unidade e de pertencimento mútuo que nos une à terra $e$ ao cosmo.

Os ambientes em que serviços à saúde são prestados propiciaram aos alunos vivências e percepções acerca de um manejo inadequado dos resíduos, demonstrando que a geração proveniente das atuações ainda não está incorporada como prática que pode ameaçar a qualidade de vida. No entanto, não é a realidade do manejo inadequado dos resíduos em si que parece apenas problemática, mas sim os métodos, instrumentos e pensamentos que parecem limitados e problemáticos. Um pensamento baseado na totalidade possibilita a emergência de uma ação mais consciente, facilita o diálogo do pensamento com a realidade, com a adversidade, com a natureza e com o outro, diminuindo os riscos de estragos que visões mutiladoras e reducionistas vêm fazendo, não apenas no mundo intelectual e científico, mas sobretudo, em nossas vidas.

Finalizando este estudo, fica evidente a necessidade de olhar para a abordagem dos resíduos sólidos de serviços de saúde no processo de formação dos cursos de graduação da área da saúde. É necessário que este saber não seja apenas uma informação de como fazer, para os aprendizes, mas que o espaço de formação propicie momentos de reflexão, de problematização, de crítica, de articulação, comprometido com a construção de sujeitos que incorporem posturas éticas, de solidariedade, consciência cidadã, compromisso social, atuando de forma responsável para com o meio.

Consideramos que, por meio da inserção da educação ambiental nas instituições de ensino superior, a transformação seja possível, trabalhando com a idéia de interdisciplinaridade, complexidade, ética, solidariedade, cooperação, cidadania, a fim de que os sujeitos que compõem esses espaços acadêmicos também sejam transformadores críticos dessa realidade com que ainda hoje nos deparamos, ou seja, de degradação ambiental, que por sua vez afeta a sociedade como um todo.

\section{Referências}

ABREU, M. C.; MASETO, M. T. O professor universitário em aula: prática e princípios teóricos. 8.ed. São Paulo: ME. ED. Associados, 1990.

ASSOCIAÇÃO BRASILEIRA DE NORMAS TÉCNICAS - ABNT. NBR 10.004. Resíduos sólidos classificação. Rio de Janeiro, 2004.

BERNA, V. Como fazer educação ambiental. São Paulo: Paulus, 2001.

BRASIL. Ministério da Educação. Resolução CNE/CES no 3, de 19 de fevereiro de 2002. Institui as diretrizes curriculares nacionais do curso de graduação em odontologia. Diário Oficial da República Federativa do Brasil. Brasília, 2002a. Seção 1, p.10.

BRASIL. Ministério da Educação. Resolução CNE/CES no 105, de 13 de março de 2002. Institui as diretrizes curriculares nacionais do curso de graduação em medicina veterinária. Diário Oficial da 
República Federativa do Brasil. Brasília, 2002b. Seção 1, p.37.

BRASIL. Ministério da Educação. Resolução CNE/CES no 3, de 7 de novembro de 2001. Institui as diretrizes curriculares nacionais do curso de graduação em enfermagem. Diário Oficial da República Federativa do Brasil. Brasília, 2001a. Seção 1, p.37.

BRASIL. Ministério da Educação. Resolução CNE/CES no 4, de 7 de novembro de 2001. Institui as diretrizes curriculares nacionais do curso de graduação em medicina. Diário Oficial da República Federativa do Brasil. Brasília, 2001b. Seção 1, p.38.

COELHO, H. Manual de gerenciamento de resíduos de serviços de saúde. Rio de Janeiro: Fiocruz, 2000.

COELHO, H. Gestão de rejeitos em saúde: como descartar, aproveitar e gerenciar. J. Assoc. Nac. Biosseg., ano 3, n.10, 2003.

CORRÊA, L. B. A educação ambiental e os resíduos sólidos de serviços de saúde: a formação acadêmica. 2005. Dissertação (Mestrado) - Programa de Pós-Graduação em Educação Ambiental, Fundação Universidade Federal do Rio Grande, Rio Grande.

FORMAGGIA, D. M. Resíduos de serviços de Saúde. In: GERENCIAMENTO DE RESÍDUOS SÓLIDOS DE SERVIÇOS DE SAÚDE, 1995, São Paulo. Resumos... São Paulo, 1995. p.3-13.

GADOTTI, M. Perspectivas atuais da educação. Porto Alegre: Artmed, 2000.

GODOY, A. S. Revendo a aula expositiva. In: MOREIRA, D. A. (Orgs). Didática do ensino superior: técnicas e tendências. São Paulo: Pioneira, 1997. p.75-82.

GRÜN, M. Ética e educação ambiental: a conexão necessária. São Paulo: Papirus, 1996.

LOUREIRO, C. F. B. Trajetória e fundamentos da educação ambiental. São Paulo: Cortez, 2004.

MANDELLI, S. M. de C. Variáveis que interferem no comportamento da população urbana no manejo de resíduos sólidos domésticos no âmbito das residências. 1997. Tese (Doutorado) - Universidade Federal de São Carlos, São Carlos.

MINAYO, M. C. S. O desafio do conhecimento: pesquisa qualitativa em saúde. 6.ed. São Paulo: HUCITEC-ABRASCO, 1999.

MORAES, M. C. Pensamento eco-sistêmico: educação, aprendizagem e cidadania no século XXI. Petrópolis: Vozes, 2004.

MORAES, M. C. Uma tempestade de luz: a compreensão possibilitada pela análise textual discursiva. Ciênc. Educação, v.9, n.2, p.191-211, 2003.

MORIN, E. A cabeça bem-feita: repensar a reforma, reformar o pensamento. 7.ed. Rio de Janeiro: Bertrand Brasil, 2002.

MORIN, E. Complexidade e transdisciplinaridade: a reforma da universidade e do ensino fundamental. Natal: EDUFRN, 1999.

PIMENTA, S. G.; ANASTASIOU, L. G. C. Docência no ensino superior. São Paulo: Cortez, 2002.

SCHNEIDER, V. E.; EMMERICH, R. C.; DUARTE, V. C.; ORLANDIN, S. M. Manual de gerenciamento de resíduos sólidos em serviços de saúde. 2. ed. rev. e ampl. Caxias do Sul: EDUCS, 2004.

SCHNEIDER, V. E.; GASTALDELLO, M. E. T.; STEDILE, N. L. R.; PLEIN, C. F.; GUERRA, L. Modelos de gestão de resíduos sólidos de serviços odontológicos (RSSO) por meio do índice de geração percapita. In: CONGRESO INTERAMERICANO DE INGENIERÍA SANITARIAY AMBIENTAL, 28., 2002, Cancun (México). Anais... Cancun: ABES, 2002. 1 CD-ROM.

STEDILE, N. L. R.; MANDELLI, S. M. D. C.; SCHNEIDER, V. E.; GASTALDELLO, M. E. T.; CLAUS, S. M.; MICHIELIN, T. L. Sistematização de fontes geradoras de resíduos sólidos de serviços de saúde como 
subsídio para proposição de programas de gerenciamento em estabelecimentos de assistência primária e secundária. In: IX SILUBESA - SIMPÓSIO LUSO-BRASILEIRO DE ENGENHARIA SANITÁRIA E AMBIENTAL, 9., 2000, Porto Seguro/Ba. Anais... Porto Seguro: ABES, 2000. p.1.477-1.486.

TAKAYANAGUI, A. M. M. Trabalhadores de saúde e meio ambiente: ação educativa do enfermeiro na conscientização para o gerenciamento de resíduos sólidos. 1993. Tese (Doutorado) Escola de Enfermagem da Universidade de São Paulo, Ribeirão Preto.

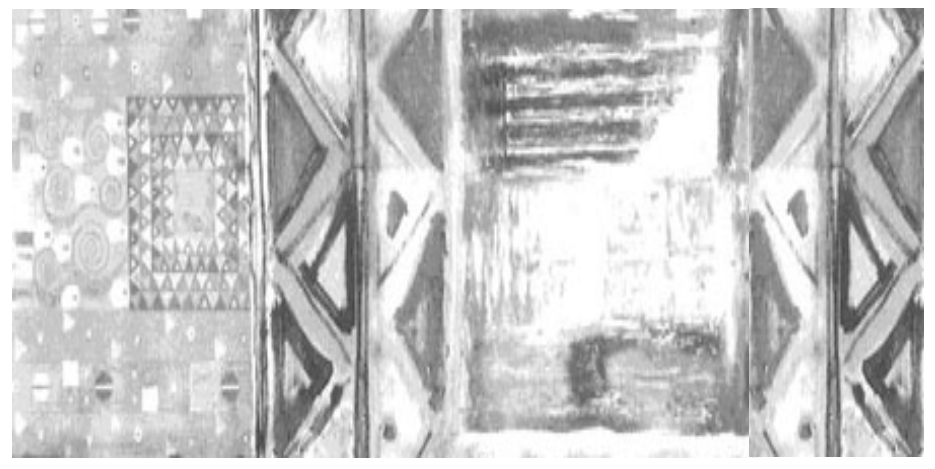

CORRÊA, L. B. et al. Conocimiento sobre residuos sólidos de servicios de salud en la formación académica: una contribución a la educación ambiental. Interface - Comunic., Saúde, Educ., v.9, n.18, p.571-84, set/dez 2005.

Este artículo demuestra como el abordaje de la problemática de los residuos sólidos de servicios de salud viene siendo construido en el proceso de formación de los cursos universitarios del área de salud. Los datos fueron colectados entre coordinadores, profesores y estudiantes de los cursos de Odontología, Medicina Veterinaria, Enfermería/ Obstetricia y Medicina de una institución pública de enseñanza superior de la región sur de Brasil. Se considera la necesidad de una reforma en la enseñanza, a fines de incluir en los procesos pedagógicos nuevas comprensiones: de integralidad, articulación, diálogo, problematización, para preparar los futuros profesionales para la instrumentalización y para hacer frente al problema de los residuos sólidos de servicios de salud, con responsabilidad y compromiso.

PALABRAS CLAVE: proceso de formación. educación superior. residuos sólidos. servicios de salud. educación ambiental. compromiso social. 